\title{
Osteochondral defects in the ankle: why painful?
}

\author{
C. Niek van Dijk • Mikel L. Reilingh • \\ Maartje Zengerink - Christiaan J. A. van Bergen
}

Received: 8 December 2009/Accepted: 11 January 2010/Published online: 12 February 2010

(C) The Author(s) 2010. This article is published with open access at Springerlink.com

\begin{abstract}
Osteochondral defects of the ankle can either heal and remain asymptomatic or progress to deep ankle pain on weight bearing and formation of subchondral bone cysts. The development of a symptomatic OD depends on various factors, including the damage and insufficient repair of the subchondral bone plate. The ankle joint has a high congruency. During loading, compressed cartilage forces its water into the microfractured subchondral bone, leading to a localized high increased flow and pressure of fluid in the subchondral bone. This will result in local osteolysis and can explain the slow development of a subchondral cyst. The pain does not arise from the cartilage lesion, but is most probably caused by repetitive high fluid pressure during walking, which results in stimulation of the highly innervated subchondral bone underneath the cartilage defect. Understanding the natural history of osteochondral defects could lead to the development of strategies for preventing progressive joint damage.
\end{abstract}

Keywords Osteochondral defect · Cartilage ·

Ankle joint $\cdot$ Subchondral cyst $\cdot$ Natural history $\cdot$ Pain

\section{Introduction}

An osteochondral defect (OD) of the talus is a lesion involving the talar articular cartilage and its subchondral bone mostly caused by a single or multiple traumatic events, but idiopathic OD of the ankle do occur [8, 46, 47, 50]. The defect initially may consist only of cartilage

C. N. van Dijk $(\bowtie) \cdot$ M. L. Reilingh · M. Zengerink ·

C. J. A. van Bergen

Department of Orthopaedic Surgery, Academic Medical Center,

University of Amsterdam, PO Box 22660, 1100 DD Amsterdam,

The Netherlands

e-mail: m.lammerts@amc.uva.nl; m.l.reilingh@amc.nl damage caused by shearing stresses, with the subchondral bone intact, but a bone contusion following high-impact force also can cause a defect [41, 62, 65]. Ankle trauma associated with an OD often leads to subchondral bone cysts. These cysts are associated with persistent deep ankle pain thereby limiting the patients mobility.

Most ODs of the talus are localized on the anterolateral or posteromedial talar dome [70]. Lateral lesions are usually shallow oval shaped and are caused by a shear mechanism. Medial lesions in contrast are usually deep, and cup-shaped, indicating a mechanism of torsional impaction and axial loading [4, 11, 12, 19, 58, 66].

Even though elaborate knowledge exists concerning ODs of the talus, its etiology and pathogenesis are still not fully understood. Increasing attention is paid to invasive and sometimes expensive surgical treatments, while research for pathogenesis of the lesions has somewhat been neglected. In order to treat ODs in all its dimensions, more should be known about their natural history. The development of an OD may have a sudden onset, but the development of a subchondral cyst is most often a slow process.

Why do some ODs remain asymptomatic and inert, while others develop pain on weight bearing, demonstrate persistent bone edema on magnetic resonance imaging and result in the progressive formation of a subchondral cyst? Understanding this process might make it possible to interfere and prevent progressive damage to the joint. In this manuscript, the most important factors related to the development of ODs are analyzed.

\section{Etiology}

A traumatic insult is widely accepted as the most important etiologic factor of an OD of the talus. For lateral talar 
defects, trauma has been described in 93-98\% and for medial defects in $61-70 \%[19,66]$. As not all patients report a history of ankle injury [17], a subdivision can be made in the etiology of nontraumatic and traumatic defects.

Ischemia, subsequent necrosis and possibly genetics are etiologic factors in nontraumatic ODs [50]. Furthermore, ODs in identical twins and siblings have been described [1, $16,68]$. The defect is bilateral in $10 \%$ of patients [23].

Traumatic cartilage injuries generally comprise three categories: microdamage or blunt trauma, chondral fractures and osteochondral fractures [20]. Ankle sprains have a predominant role in traumatic ODs. When a talus twists inside its boxlike housing during an ankle sprain, the cartilage lining of the talus can be damaged. This may lead to a bruise and subsequent softening of the cartilage or even a crack in the cartilage with subsequent delamination.

Separation in the upper layer of the cartilage occurs as a result of shearing forces. Alternatively, separation may occur in the subchondral bone, giving rise to a subchondral bone lesion. Fragments may break off, and float loose in the ankle joint, or they remain partially attached and stay in position. The lesions can either heal and remain asymptomatic or progress to deep ankle pain on weight bearing and formation of subchondral bone cysts.

In cadaver ankles, Berndt and Harty reproduced lateral defects by strongly inverting a dorsiflexed ankle. As the foot was inverted on the leg, the lateral border of the talar dome was compressed against the face of the fibula [4]. When the lateral ligament ruptured, avulsion of the chip began. With the use of excessive inverting force, the talus within the mortise was rotated laterally in the frontal plane, impacting and compressing the lateral talar margin against the articular surface of the fibula. A portion of the talar margin was sheared off from the main body of the talus, which caused the lateral OD. A medial lesion was reproduced by plantarflexing the ankle in combination with slight anterior displacement of the talus on the tibia, inversion and internal rotation of the talus on the tibia.

\section{Clinical presentation}

In the acute situation, an OD of the talus often remains unrecognized since the swelling and pain from the lateral ligament lesion prevails. The weight-bearing anteroposterior (mortise) and lateral radiographs may not reveal any pathology, or only show an area of radiolucency. In case of a large OD the initial radiographs may be positive. When the symptoms of the ligament injury have resolved after some weeks, symptoms of persistent swelling, limited range of motion and pain on weight bearing may continue. If symptoms have not resolved within 4-6 weeks, an (osteo)chondral defect should be suspected. Locking and catching are symptoms of a displaced fragment.

Chronic lesions typically present as persistent or intermittent deep ankle pain during or after activity [18]. Most patients demonstrate a normal range of motion with absence of recognizable tenderness on palpation and absence of swelling. However, reactive swelling or stiffness may be present.

The natural history of osteochondral lesions of the talus whether treated or not is benign. We reported the long-term results of ODs and found only one case of radiographic progression after 10 years in 38 cases [52]. Reports of ankle arthrodesis following ODs of the talus are rare [18, 52].

\section{Cartilage and bone anatomy}

Cartilage consists of chondrocytes that lie groupwise in lacunae of the extracellular matrix they produce. The cartilaginous matrix consists of collagen, hyaluronic acid, proteoglycans and a small amount of glycoprotein's (Fig. 1). Its elasticity is based on the electrostatic connections between collagen fibers and the glycosaminoglycan (GAG) side chains of the proteoglycans, the containment of water by the negatively loaded GAGs of the central protein of proteoglycans and the flexibility and the mutual sliding of the collagen fibers.

Cartilage is avascular and is nourished by the intraarticular fluid. The tissue fluid of the cartilage matrix, which

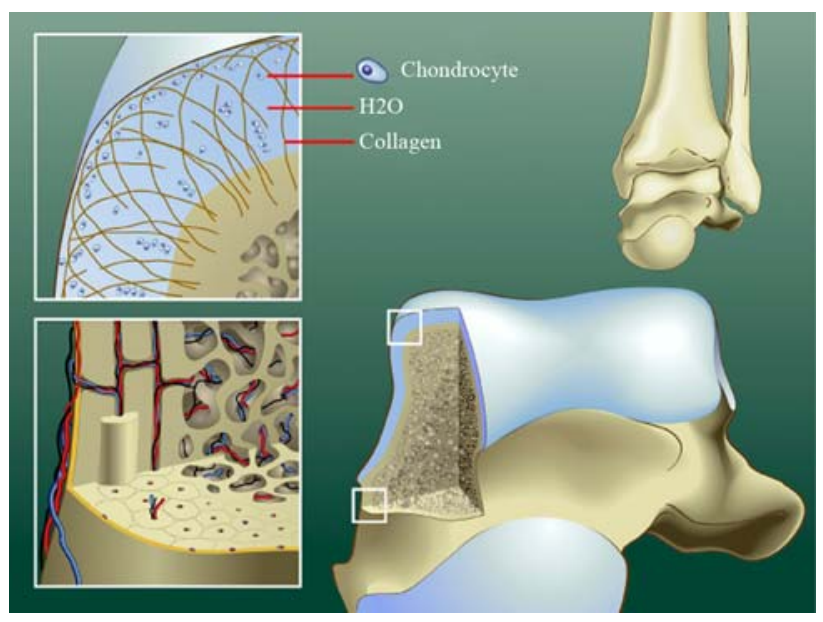

Fig. 1 Schematic diagrams showing normal anatomy of ankle cartilage, subchondral plate and subchondral bone area. The cartilage consist of chondrocytes that lie groupwise in lacunae of the extracellular matrix, which contains collagen fibers in an arcwise configuration, hyaluronic acid, proteoglycans and $75 \%$ water (upper left). The hollow haversian canal that runs longitudinally down the center of the osteon in compact bone contains an arteriole, venule and lymphatic duct for vascular and lymphatic drainage. The Volkmann canals run perpendicular to and connect the Haversian canals (lower left) 
comprises about $75 \%$ of the total weight of the cartilage, functions as a transport medium. In the healthy cartilage the GAG side chains of the proteoglycans play an important role for the elasticity and maintenance of the water content of $75 \%$. As a matter of fact, we all walk on water. Cartilage does not contain lymph vessels or nerves and has a slow metabolism [27]. Mineralized bone consists of both compact and trabecular bone. Compact bone is found beneath the periosteum and acts as the main weight-bearing pillar for the skeleton. It is not a solid tissue but rather an aggregation of osteons, the major multicellular unit of compact bone. Each osteon is composed of groups of concentric calcified cylinders, each of which is made up of bone matrix proteins that form long cylinders-shaped structures, oriented parallel to the long axis of the bone [33].

\section{Histopathology}

Koch et al. studied the cartilage and bone morphology in ODs of the knee [29]. They intra-operatively harvested cylinders of the osteochondral areas as part of a cartilagebone transplantation in 30 patients. At the cartilage level there was a loss of acidic GAGs from the extra-cellular matrix and a decrease of the number of chondrocytes. Hyaline cartilage was often replaced by fibrocartilage. The subchondral bone plate was thinned compared to normal osteochondral samples and had fractured areas. Parallel with a general loss of proteoglycans from the superficial layers of the extracellular cartilage matrix, the amount of chondroitin sulfates and keratin sulfate was increased in deep cartilage layers and in the subchondral bone. Koch et al. [29] stated that all morphological features tend to indicate that the main area of action is around the subchondral bone plate.

In 2009 Uozumi et al. [63] studied the differences in the histological findings of ODs in 12 knees. During the surgery, cylinder osteochondral plugs were taken from the center of the OD and examined with light microscopy. They classified three types in the subchondral bone area: (1) necrotic subchondral trabeculae, (2) viable subchondral trabeculae, and (3) cartilage without bone trabeculae. Uozumi et al. [63] stated that the initial change in the subchondral area is bone necrosis or subchondral fracture; the necrotic bone is then absorbed and replaced either by viable subchondral trabeculae or cartilage without bone trabeculae.

An abnormal subchondral plate is likely to be one of the major factors in influencing the long-term outcome of articular cartilage repair. Qiu et al. [40] studied ODs in femoral condyles of rabbits and found that the presence of an advanced and irregular subchondral plate was associated with degradation of repaired articular surface.

\section{Cause of pain in osteochondral ankle lesions}

Several factors can play a role in the cause of pain in ODs. A raise in intra-osseous pressure has been mentioned as a cause of pain and has been associated with joint degeneration [2, 3, 64]. Restoration or decrease in the intra-osseous pressure can be accomplished by medullary decompression [28, 57].

A rise in intra-articular pressure can be a cause of pain in degenerative joint disease. Goddard and Gosling have found a linear correlation between experience pain in osteoarthritis and resting intra-articular pressure of the synovial fluid [21]. A connection of synovial hypertrophy and raised intra-articular pressure in arthritis has been demonstrated by Bünger et al. [10]. However, it is unlikely that in a localized osteochondral talar defect a raise in intra-articular pressure plays a role. These patients typically do not demonstrate relevant joint effusion.

Nerve endings can be found in the synovium and joint capsule. Joint capsule and the soft tissue around the joint are important triggers of nociception. The upregulation of substance P- and CGRP-positive neurons in response to arthritic changes suggests a mechanism involving neuropeptides in the maintenance of a painful degenerative joint disease [49]. Patients with an OD of the ankle, however, generally do not show much synovitis. The synovium of the anterior ankle joint can be palpated since it lies directly under the skin. These patients usually can differentiate this secondary synovial pain from the deep ankle pain caused by the OD. The disabling deep ankle pain on weight bearing cannot be reproduced during physical examination. The most probable cause of this pain is the nerve endings in the subchondral bone that have been firstly detected in the early nineties [33].

Within each osteon a hallow tube, known as a Haversian canal, runs longitudinally down the center of the osteon. It contains an arteriole, venule and lymphatic duct to provide the vascular and lymphatic drainage of compact bone. In addition to the longitudinally oriented Haversian canals, a series of canals known as Volkmann's canals run perpendicularly to and interconnect the Haversian canals (Fig. 1). Mach et al. [33] studied mouse femora and found that not all osteons are innervated. The likelihood of an osteon being innervated is greatest in the proximal head followed by the distal head and then the diaphysis of the femur. There are CGRP-immunoreactive and RT-97 (clone name of neurofilament) immunoreactive nerve fibers, which suggests that the mineralized bone, the bone marrow and the periosteum are innervated by both unmyelinized and myelinized fibers. These fibers contain A- $\beta, \mathrm{A}-\delta$ and $\mathrm{C}$-fibers that conduct sensory input from the periphery to the spinal cord. In general, the areas in mineralized bone that underwent the greatest mechanical stress and loading, 
that had the highest metabolic rate, and that were most vascularized, had the highest density of sensory and sympathetic fibers [33]. The fact that there is abundant innervation of bone marrow possibly explains the observation that patients with bone diseases already experience pain before there is any radiological evidence of bone destruction or involvement of the periosteum. Macrophages, the precursor cells of the osteoclasts, form important accessory cells in the regulation of bone metabolism and destruction. Chronic macrophage activation and vascular derangements lead to low PH, local bone demineralization (acid attack), and $\mathrm{H}^{+}$-mediated stimulation of the primary afferent nociceptive nerve fibers [31]. Pain probably develops as a rise in fluid pressure, and a decrease in $\mathrm{pH}$ excitates nerve fibers present in bone.

\section{Joint congruency versus cartilage thickness}

The cartilage of the talar dome is thin in comparison with the cartilage of other articulating surfaces. The average cartilage thickness of the talar dome is $1.11( \pm 0.28 \mathrm{~mm})$ in women and $1.35( \pm 0.22 \mathrm{~mm})$ in men [59]. Shepherd and Seedhom [55] found almost similar values. In 1891, Braune and Fischer [5] proposed that articular cartilage is thicker in regions of low congruence. Simon et al. [56] related joint congruence to cartilage thickness. They calculated congruence ratios for canine joints by dividing the average length of the congruent surface by the average length of the total articular surface. The ankle with the thinnest articular cartilage had the highest ratio, and the knee with the thickest cartilage had the lowest ratio. Shepherd and Seedhom [55] conducted a similar study with human cadaver specimens. The average thickness of the cartilage in the ankle, hip, and knee joints were $1.2 \mathrm{~mm}$ (1.0-1.6), $1.6 \mathrm{~mm}$ (1.4-2.0) and $2.2 \mathrm{~mm}$ (1.7-2.6), respectively. The thickness of the cartilage appeared to be related to the congruence of a joint. Shepherd and Seedhom [55] hypothesized that congruent joint surfaces, such as those in the ankle and elbow, are covered only by thin articular cartilage because the compressive loads are spread over a wide area, decreasing local joint stresses and eliminating the necessity for large cartilaginous deformations. Incongruent joints are covered by thicker cartilage which more easily deforms, thereby increasing the load-bearing area and decreasing the stress per unit area.

\section{Cartilage, subchondral bone and loading}

Tissue changes the structure in response to the functional demands imposed on them. Connective tissue has the ability to alter structure in response to mechanical loading.
Adaptation is affected by different cells. Cartilage has a much lower response to mechanical adaptation when compared to bone. Bone remodeling is regulated by osteocytes that respond to mechanical triggers by sending signals that promote osteoblastic bone formation. Osteoclasts resorb bone at the site of microcracks that frequently occur in the subarticular spongiosa during impact loading. Large number of osteoclasts digesting parts of the bone plate lie in close contact to osteoblasts that seem to be compensating for bony instability by constantly remodeling the bone stock. Loading tends to thicken the subchondral bone plate in cases of overlying cartilage damage. This results in sclerosis of the subchondral bone plate.

The load-bearing area of the ankle joint is relatively small compared to the forces it conducts. The load on the ankle joint during walking can be calculated. Procter and Paul measured the load to be 3.9 times body weight at heel rise during the stance phase of walking [39] (Fig. 2). Mow et al. measured a load of 5.0 times body weight at heel rise during the stance phase of walking [37]. Hence, according to the data of Procter and Paul, the force on the talus with every step taken by a person weighing $75 \mathrm{~kg}$ is $2,867 \mathrm{~N}$ $\left(3.9 \times 75 \mathrm{~kg} \times 9.8 \mathrm{~m} / \mathrm{s}^{2}\right)$. The average tibiotalar contact area is estimated to be $4.4 \mathrm{~cm}^{2}$ [44]. This means that the average load on the articular cartilage during the stance phase can be calculated to be $650 \mathrm{~N} / \mathrm{cm}^{2}$. During running, this load increases multiple times.

When the contact surface areas diminish in size, this will result in an increase in load on the remaining cartilage. This happens in malunion after an ankle fracture. Ramsey and Hamilton [44] have shown that 1-mm lateral talar shift reduces the contact area by $42 \%$, while $2-\mathrm{mm}$ lateral shift reduces the contact area by $56 \%$. Lloyd et al. [32] found similar values. In the latter situation the average load per
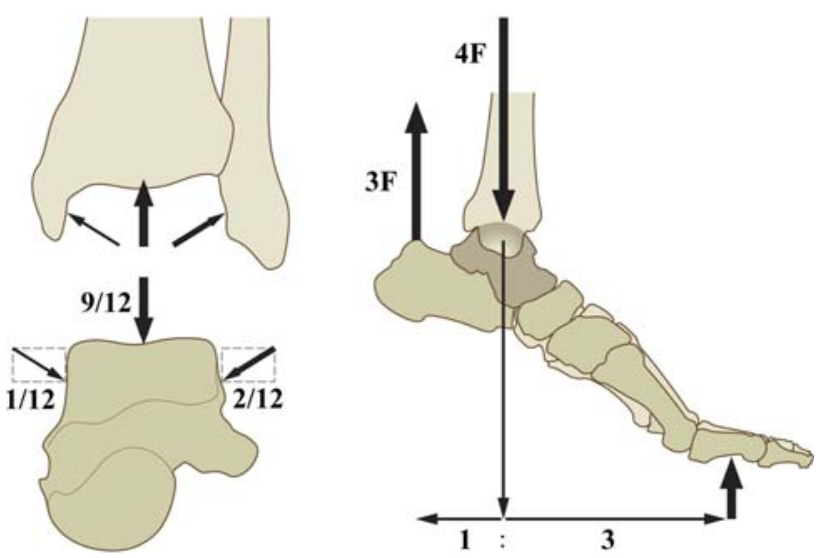

Fig. 2 Schematic diagrams showing the calculation of load transmission through the ankle joint during walking. Approximately one-sixth of the load across the ankle is transmitted through the talofibular facet, and the remaining load is transmitted through the tibiotalar articulation. $F=$ force 
$\mathrm{cm}^{2}$ in a person of $75 \mathrm{~kg}$ is increased from 650 to $1590 \mathrm{~N}$ (Fig. 3). A 2-mm shift is thus an indication for correction and operative reduction because of the high risk of developing degenerative changes [26]. A 1-mm shift is generally regarded to be acceptable. This would mean that talar cartilage can adept to an increase in load of up to $40 \%$ !

In the case of an OD the following calculation can be made. The size of an average defect measures $0.85 \mathrm{~cm}^{2}$ on magnetic resonance imaging (MRI) [15]. By means of computed tomography (CT) we measured the size of the talar OD in 50 consecutive patients that were treated for a symptomatic OD. We measured an average defect size of $0.65 \mathrm{~cm}^{2}\left(0.5-0.8 \mathrm{~cm}^{2}\right)$. The size of an OD can easily be overestimated on MRI because of bone edema, this can explain the difference. After debridement of a talar OD with a diameter of $0.65 \mathrm{~cm}^{2}$ it can be calculated that the load on the remaining talar cartilage is increased by $15 \%$ (Fig. 3). This increase in load is probably not enough to cause damage to the remaining cartilage since this figure lies far beyond the threshold of $40 \%$. Any varus or valgus malalignment can increase the load [7] and hence increase the likelihood of progressive cartilage damage [9, 42, 60].

Radin and Paul [43] argued that articular cartilage by virtue of its thinness is not a good shock absorber considered in terms of reduction of peak impact force. Although the underlying bone is much stiffer, it is so much longer by comparison, that its total compliance exceeds that of cartilage. Peak stresses at the joint surface, however, are still greatly reduced through redistribution and deformation of

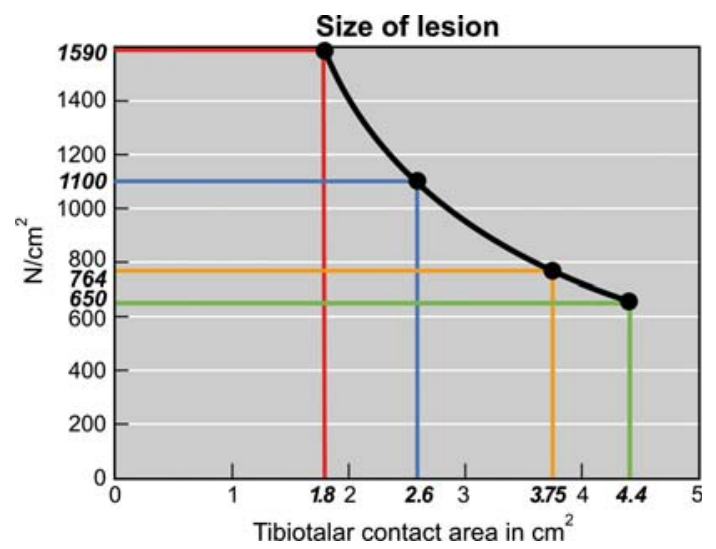

Fig. 3 Graph showing load in relation to tibiotalar contact (black line). The green line represents the average tibiotalar contact area of $4.4 \mathrm{~cm}^{2}$ for a $75-\mathrm{kg}$ person during the stance phase of walking. The blue line represents the same person with a tibiotalar contact area diminished by $42 \%$ to $2.6 \mathrm{~cm}^{2}$, as would occur after an ankle fracture with $1 \mathrm{~mm}$ of lateral displacement of the talus and fibula. The red line represents the same person with a tibiotalar contact area diminished by $58 \%$ to $1.8 \mathrm{~cm}^{2}$, as would occur after an ankle fracture with $2 \mathrm{~mm}$ of lateral displacement of the talus and fibula. The yellow line represents a person weighing $75 \mathrm{~kg}$ with an OD of the talus measuring $0.65 \mathrm{~cm}^{2}$; the average load on the remaining cartilage is increased from 650 to $764 \mathrm{~N} / \mathrm{cm}^{2}$ cartilage. In contrast to the tibia, which is a long bone, the talus is compact, and peak impact force can only be distributed over a small volume of bone. The small talar volume combined with its thin cartilage may explain why ODs are more common on the talar dome than in the tibial plafond.

Thin cartilage is less elastic when compared to thick cartilage. Shepherd and Seedhom [55] suggested an inverse relation between the mean cartilage thickness and mean compressive modulus, i.e., thin cartilage has a high compressive modulus. After measuring cadaver cartilage of several species including humans, they found that two factors contribute to the deformability of the cartilage: the thickness of the cartilage and its intrinsic elasticity. There is a curvilinear relationship between the magnitude of the deformation and the thickness of the articular cartilage under a certain level of loading. In the congruent ankle joint, Wan et al. measured a peak cartilage deformation of $34.5 \% \pm 7.3 \%$ under full body weight in persons with a medial talar dome cartilage thickness of $1.42 \pm 0.31 \mathrm{~mm}$ [67] (Fig. 4).

Talar cartilage is thin and therefore less elastic. It makes the talus more susceptible to cartilage lesions and

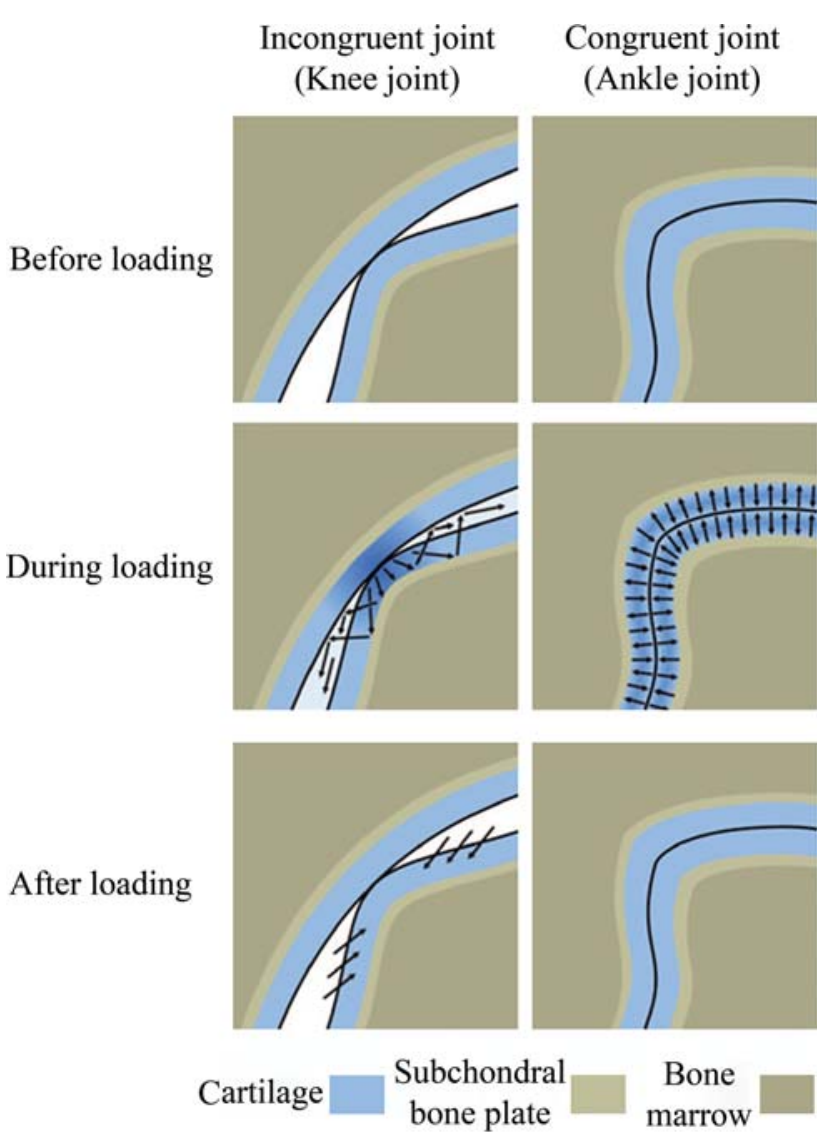

Fig. 4 Schematic comparison of the deformation of the cartilage in a congruent (ankle) and incongruent (knee) joint before, during and after loading. Arrows $=$ direction of water 
microfractures in the underlying bone when exposed to high-impact forces. However, ODs occur in joints with thicker cartilage as well and whether or not an OD occurs probably also depends on factors like impact force and shearing stress.

Cartilage has two components that enable the tissue to withstand compressive stress: a liquid and a multicomponent solid consisting of collagen and hydrophilic proteoglycan molecules. The liquid is a dialysate of synovial fluid that is incompressible, but able to flow. However, for this fluid to withstand the compressive loads that joints sustain, it must be contained. The cartilage matrix resembles a sponge with directional pores. The small diameter of these functional pores and their arrangement in circuitous tunnels, created by the hydrophilic collagen end proteoglycan matrix components, prevent large molecules from entering the cartilage and offer considerable resistance to interstitial fluid flow. These characteristics provide adequate containment for the fluid to support the load. At any instant, only a part of the joint is load-bearing or compressed. If one part is in compression, the adjacent area is being stretched and pulled apart and liquid flows to the unloaded area. In a healthy situation, the liquid is not able to enter the subchondral plate. It will only flow to adjacent cartilage. Fluid in cartilage is freely exchangeable, whether extra- or intra-fibrillar [34]. Herberhold et al. [22] studied patellar and femoral compression for $4 \mathrm{~h}$ under continuous static loading with $150 \%$ body weight. A maximal thickness reduction of $57 \pm 15 \%$ was observed for patellar cartilage and a volume change of $>30 \%$, suggesting that more than $50 \%$ of the interstitial fluid were displaced from the matrix.

However, when trauma has caused microfractures in the subchondral plate and subchondral bone it creates a situation in which liquid not only flows within the cartilage, but it can enter into the subchondral bone through the microfractured area. Damaged subchondral bone is less able to support the overlying cartilage [9]. Inadequate subsurface support from an abnormal subchondral bone might be one of the main reasons for unsuccessful cartilage repair [35, 40, 54]. Cartilage that is not supported by the underlying bone plate loses proteoglycans and glycoprotein [27, 43]. The loss of negatively loaded GAG side chains and hydrophilic proteoglycans causes a decrease in containment of water; it flows more easily to other places. Each step or other load-bearing activity causes water to be pressed out of the cartilage and pressed into the microfractured areas of the subchondral bone (Fig. 5).

It has been demonstrated that continuous high fluid pressure causes osteolysis. An intermittent or continuous high local pressure can interfere with normal bone perfusion and lead to osteonecrosis, bone resorption and formation of lytical areas [2, 3, 14, 25, 51, 64] (Fig. 6). These changes in structure at the level of the subchondral bone are induced by mechanical forces, gravity, compression, fluid shear stress and hydrostatic pressure. In the undiseased situation we can say that "form follows function".

Irie et al. [24] studied calcitonin gene-related peptide (CGRP)-containing nerve fibers in bone tissue and their involvement in bone remodeling. The effect of CGRP on bone remodeling could be partly through its action on blood vessels, regulating local blood flow. Possibly high fluid pressures cause excitation of CGRP-containing nerve fibers, thereby diminishing blood flow through bone, and causing osteolysis. Compression of incompressible fluid leads to local stress shielding. It is postulated that as long as the fluid pressure is preserved, the bone resorption will continue. When the fluid pressure drops, the resorption stops. Bone remodeling around the cystic bone defect will create a layer of dense bone adjacent to the cavity thus creating a sclerotic cystic wall.

When the subchondral bone lies exposed because overlying cartilage is sheared off or because the cartilagebone interface is damaged at microscopic level, it is subject
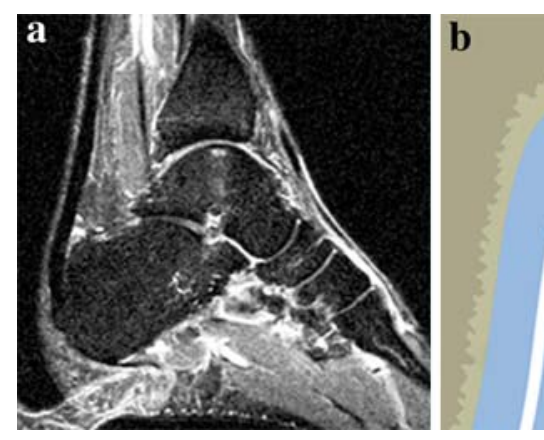

Fig. 5 a Sagittal T2-weighted MRI study of an ankle with an OD. The vertical configuration of the water column (seen in the center of the talus) suggests that the water is pumped directly caudal under high pressure, perpendicular to the talar joint surface. $\mathbf{b}$ and $\mathbf{c}$, Schematic diagrams of fissures in the subchondral bone plate of an unloaded
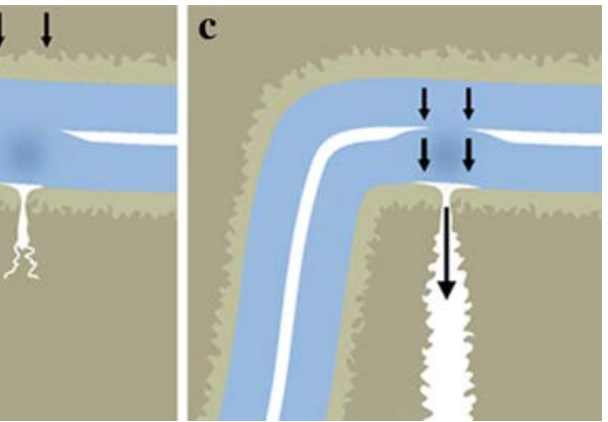

ankle $\mathbf{b}$ and a loaded ankle $\mathbf{c}$. When the ankle is loaded, the water is squeezed out of the cartilage into the subchondral bone. The diameter of the opening of the subchondral bone plate determines the pressure of the fluid flow (the smaller the diameter, the higher the pressure) 
Fig. 6 a through c, Coronal CT scans (upper row) with corresponding schematic diagrams (lower row), showing the ankles of three young patients (26-37 years), who had deep ankle pain of 5-12 years duration. An opening in the subchondral bone plate can be seen in all three CT scans, with subchondral osteolysis that has developed into a subchondral cyst. a Coronal CT, showing a cystic lesion in the talar body, with corresponding diagram schematically indicating the mechanism of cyst formation. Black lines $=$ nerve endings in subchondral bone. b, In this patient, the cyst has extended to the subtalar joint. c, Sclerosis is visible around the subtalar cyst
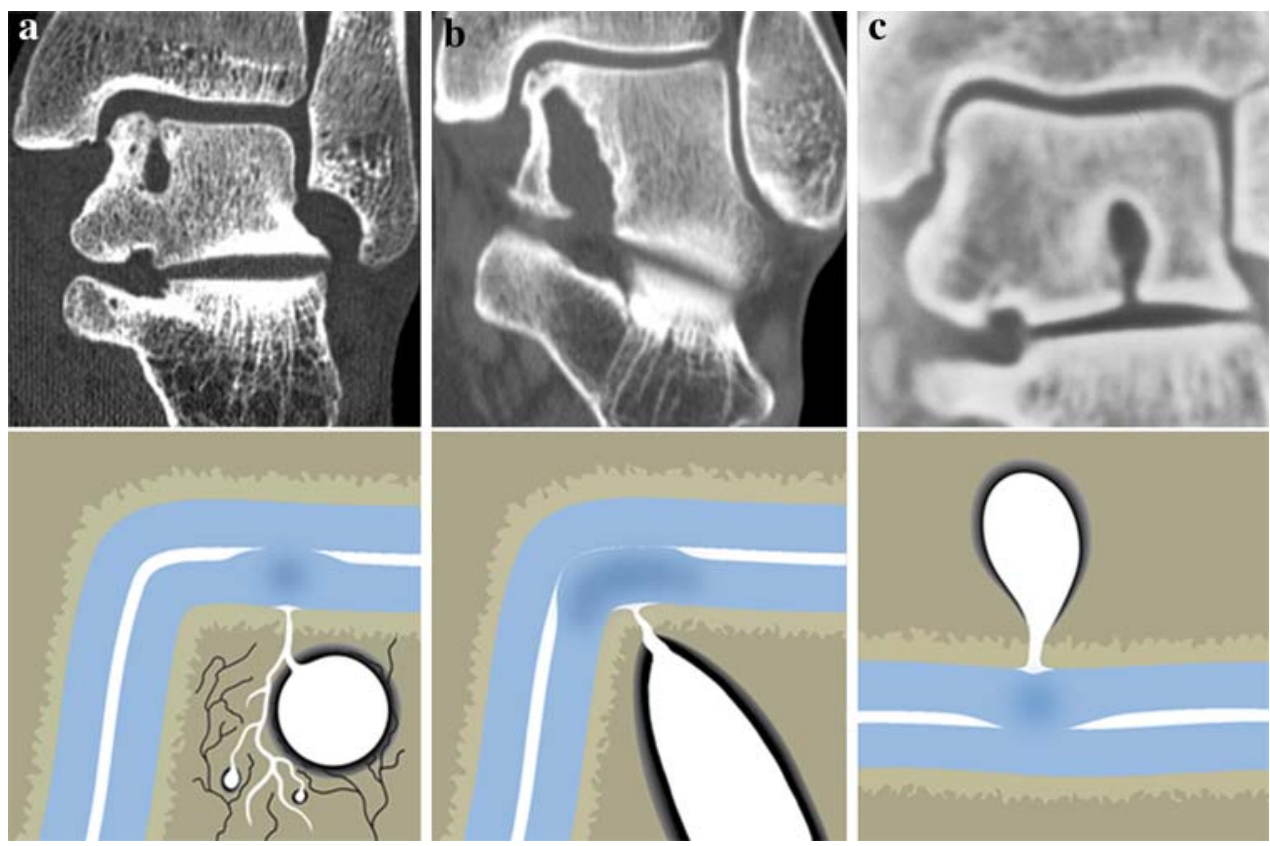

to continuous high fluid pressures that cause osteolysis and subsequent large defects [14, 45, 69]. The subchondral bone becomes damaged because of damaged overlying cartilage and the cartilage damages further because the underlying bone is unable to provide support. This way, a vicious circle is started.

\section{Various types of osteochondral defects in the ankle}

There are various factors that may play a role in the development of ODs in the ankle. The ankle joint has a high congruency. A decrease in joint congruence will increase contact pressure per area. More displacement corresponds to increasing contact pressure [32, 44]. Thordarson et al. confirm that substantial displacement of the fibula $\left(\geq 2 \mathrm{~mm}\right.$ shortening or lateral shift or $\geq 5^{\circ}$ external rotation) increases the contact pressures in the ankle joint [61]. Long-term follow-up studies have demonstrated that patients with persistent displacement of ankle fractures had poorer long-term results than those without persistent displacement [26]. Therefore, displacement of $>2 \mathrm{~mm}$ of the fibula in injuries should not be accepted.

Varus or valgus malalignment of the ankle joint may also play an important role in the natural history by increasing the contact pressure in certain localizations of the ankle. Biomechanical experiments have demonstrated that in varus and supination the maximum pressure is located on the medial border of the talus, while in valgus and pronation the maximum pressure is located on het lateral talar border [7]. Increased pressure on an existing
OD may negatively influence the healing of the defect [9, 14, 30, 42]. Koshino et al. [30] observed the medial joint space in 146 knees during the removal of blade plate after a high tibial valgus osteotomy 2 years postoperatively. They found a clear relationship between the stage of cartilage regeneration and the postoperative limb alignment, with more mature regeneration seen in more valgus angulated knees. It is therefore important to detect and correct malalignment in patients with an OD of the talus.

The consecutive stages of local ODs may help us to understand the development of the defects. Superficial lesions consist of sheared off flakes with an intact subchondral bone plate (Fig. 7). In a more severe defect, the subchondral bone is damaged, as with, microfractures and bone bruises. Bone bruises are seen as a decreased signal intensity on T1-weighted MRI studies and an elevated intensity on T2-bone MRI. The reticular type bone bruise is not continuous with the adjacent articular surface $[6,38$, 65] (Fig. 8). In general, this type heals normally and the healing occurs from the periphery to the center [13]. The geographic type bone bruise is continuous with the adjacent articular surface (Fig. 9). It is this type that is often associated with ODs of the talus. Spontaneous healing is impaired or absent [38, 48, 65]. This impaired healing could possibly be caused by the cartilaginous water content being forced -on every step- into the persistent fissure in the bone plate underneath. In case of an osteochondral fragment, healing may be precluded by intermittent fluid flow on every step around the fragment (Fig. 10).

Subchondral cyst formation has been hypothesized to be caused by the damaged cartilage functioning as a valve [53]. This valve mechanism would allow intrusion of fluid 
Fig. 7 a MRI study showing a cartilage defect of the medial talar dome. The subchondral bone plate has remained intact, and there is no sign of bone showing a fragment that probably was sheared from the underlying bone bruise. b Schematic diagram
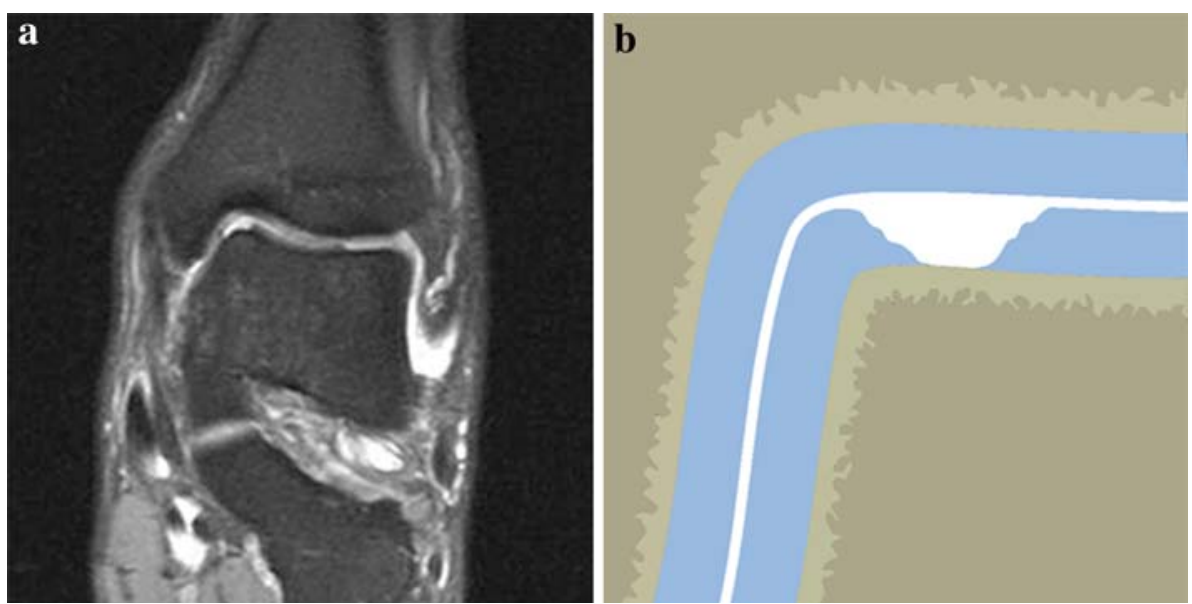

Fig. 8 a Sagittal T2-weighted MRI study of an ankle with a reticular bone bruise. The white area in the anterior talus represents bone edema. b Schematic diagram of a reticular bone bruise with intact subchondral bone plate. This type of bone bruise heals from the periphery to the center without complications
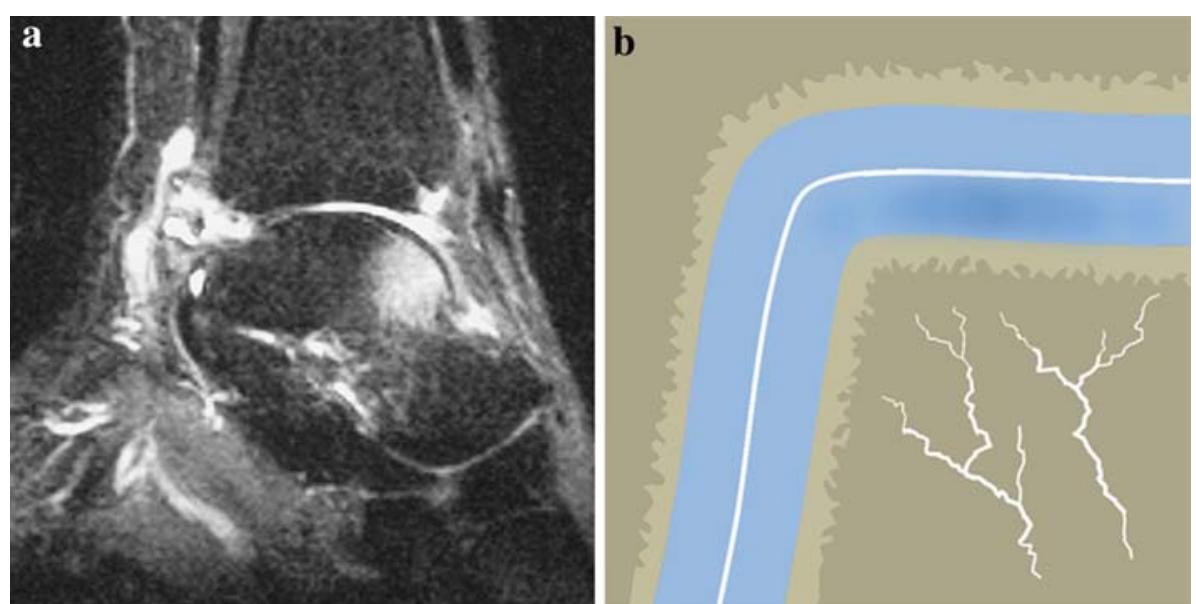

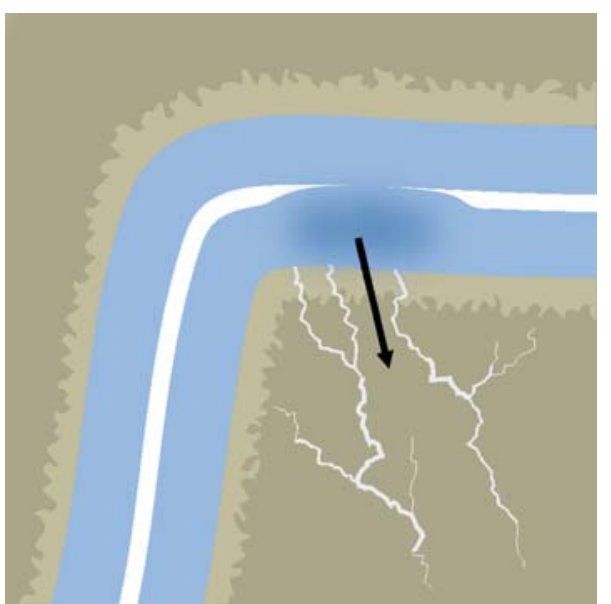

Fig. 9 Schematic diagram showing the geographic type of bone bruise, which is continuous with the adjacent articular surface. Healing depends of the healing of the subchondral bone plate

from the joint space into the subchondral bone, but not in the opposite direction. On the weight-bearing phase of gait there is full contact between major parts of the talar and tibial cartilage, with most contact over the talar shoulders [36]. During this phase, pressures in opposing talar and tibial cartilage are theoretically identical, which may result in the forcing of fluid in the direction of the least resistance, i.e., the damaged subchondral bone. Backflow is prevented by the direct contact of opposing cartilage. During unloading of the joint, joint space fluid may re-enter the articular cartilage. On the next weight-bearing cycle, this fluid again is intruded in the subchondral bone. This repetitive mechanism represents a vicious circle, causing the intermittent shift of synovial fluid under high pressure into the damaged subchondral talar bone. Development of a subchondral cyst is then just a matter of time.

\section{Conclusion}

Most osteochondral talar defects are caused by trauma. They may heal and remain asymptomatic or progress to subchondral cysts with deep ankle pain on weight bearing. The pain in osteochondral defects is most probably caused by an intermittent local rise in intraosseous fluid pressure 
Fig. 10 Schematic diagrams showing a loose osteochondral fragment when the ankle is unloaded (a) and loaded (b). Healing under loading may be precluded by intermittent fluid flow around the fragment
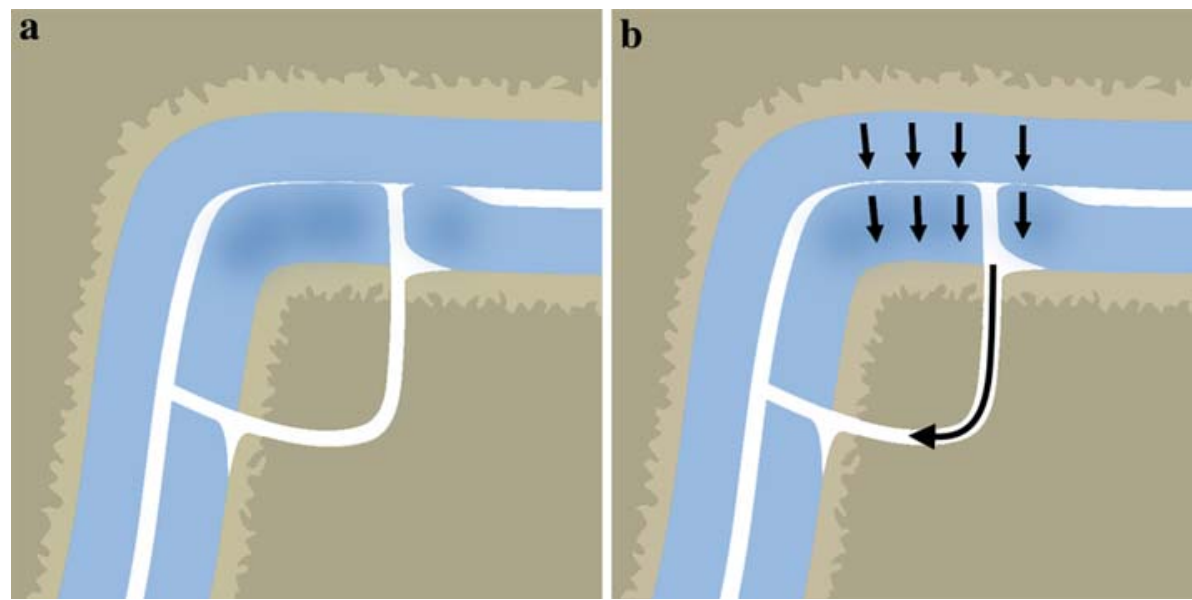

with occurs on every step, and which thus sensitizes the highly innervated subchondral bone. The development of symptoms and subchondral cysts depends on the defect type, joint congruence, alignment, impact force and shearing stress. Symptoms and subchondral cyst formation will only occur in case of a local small diameter defect in the subchondral plate.

Cartilage has a liquid and a solid component (i.e., collagen and proteoglycans) that enables it to withstand compressive stress. A congruent joint surface, such as the ankle, is covered by thin articular cartilage. Incongruent joints, such as the knee, are covered by thicker cartilage. There is a curvilinear relation between the cartilage thickness and deformation. Thick cartilage easily deforms, thereby increasing the load-bearing area and decreasing the stress area.

Fluid from the damaged cartilage can be forced into the microfractured subchondral bone plate underneath during loading. The smaller the diameter of the defect in the subchondral plate, the higher the fluid pressure. This intermittent local rise in high fluid pressure will cause osteolysis and the eventual formation of a subchondral cyst. Malalignment of the ankle joint may aggravate this process by increasing the local pressure in specific locations of the ankle. The pain in osteochondral defects is most probably caused by the repetitive high fluid pressure and decrease in $\mathrm{pH}$, sensitizing the highly innervated subchondral bone.

Acknowledgments L. Blankevoort, $\mathrm{PhD}$, is gratefully acknowledged for his advice during the preparation of this manuscript. I. E. M. Kos, is gratefully acknowledged for the kind preparation of the figures.

Open Access This article is distributed under the terms of the Creative Commons Attribution Noncommercial License which permits any noncommercial use, distribution, and reproduction in any medium, provided the original author(s) and source are credited.

\section{References}

1. Anderson DV, Lyne ED (1984) Osteochondritis dissecans of the talus: case report on two family members. J Pediatr Orthop 4:356-357

2. Aspenberg P, Van der Vis H (1998) Migration, particles, and fluid pressure. A discussion of causes of prosthetic loosening. Clin Orthop Relat Res 352:75-80

3. Astrand J, Skripitz R, Skoglund B, Aspenberg P (2003) A rat model for testing pharmacologic treatments of pressure-related bone loss. Clin Orthop Relat Res 409:296-305

4. Berndt AL, Harty M (1959) Transchondral fractures (osteochondritis dissecans) of the talus. J Bone Joint Surg Am 41A:988-1020

5. Braune W, Fischer O (1891) Die Bewegungen des Kniegelenks nach einer neuen Methode am lebenden Menschen gemessen. S Hirzel, Leipzig, pp 75-150

6. Bretlau T, Tuxoe J, Larsen L, Jorgensen U, Thomsen HS, Lausten GS (2002) Bone bruise in the acutely injured knee. Knee Surg Sports Traumatol Arthrosc 10:96-101

7. Bruns J, Rosenbach B (1990) Pressure distribution at the ankle joint. Clin Biomech 5:153-161

8. Bruns J (1997) Osteochondrosis dissecans. Orthopade 26:573-584

9. Buckwalter JA, Mankin HJ (1998) Articular cartilage: degeneration and osteoarthritis, repair, regeneration, and transplantation. Instr Course Lect 47:487-504

10. Bunger C, Harving S, Hjermind J, Bunger EH (1983) Relationship between intraosseous pressures and intra-articular pressure in arthritis of the knee. An experimental study in immature dogs. Acta Orthop Scand 54:188-193

11. Canale ST, Belding RH (1980) Osteochondral lesions of the talus. J Bone Joint Surg Am 62:97-102

12. Chen DS, Wertheimer SJ (1992) Centrally located osteochondral fracture of the talus. J Foot Surg 31:134-140

13. Davies NH, Niall D, King LJ, Lavelle J, Healy JC (2004) Magnetic resonance imaging of bone bruising in the acutely injured knee-short-term outcome. Clin Radiol 59:439-445

14. Durr HD, Martin H, Pellengahr C, Schlemmer M, Maier M, Jansson V (2004) The cause of subchondral bone cysts in osteoarthrosis: a finite element analysis. Acta Orthop Scand 75:554-558

15. Elias I, Zoga AC, Morrison WB, Besser MP, Schweitzer ME, Raikin SM (2007) Osteochondral lesions of the talus: localization and morphologic data from 424 patients using a novel anatomical grid scheme. Foot Ankle Int 28:154-161 
16. Erban WK, Kolberg K (1981) Simultaneous mirror image osteochondrosis dissecans in identical twins. Rofo 135:357

17. Ferkel RD, Scranton PE Jr (1993) Arthroscopy of the ankle and foot. J Bone Joint Surg Am 75:1233-1242

18. Ferkel RD, Zanotti RM, Komenda GA, Sgaglione NA, Cheng MS, Applegate GR et al (2008) Arthroscopic treatment of chronic osteochondral lesions of the talus: long-term results. Am J Sports Med 36:1750-1762

19. Flick AB, Gould N (1985) Osteochondritis dissecans of the talus (transchondral fractures of the talus): review of the literature and new surgical approach for medial dome lesions. Foot Ankle 5:165-185

20. Frenkel SR, Di Cesare PE (1999) Degradation and repair of articular cartilage. Front Biosci 4:671-685

21. Goddard NJ, Gosling PT (1988) Intra-articular fluid pressure and pain in osteoarthritis of the hip. J Bone Joint Surg Br 70:52-55

22. Herberhold C, Faber S, Stammberger T, Steinlechner M, Putz R, Englmeier KH et al (1999) In situ measurement of articular cartilage deformation in intact femoropatellar joints under static loading. J Biomech 32:1287-1295

23. Hermanson E, Ferkel RD (2009) Bilateral osteochondral lesions of the talus. Foot Ankle Int 30:723-727

24. Irie K, Hara-Irie F, Ozawa H, Yajima T (2002) Calcitonin generelated peptide (CGRP)-containing nerve fibers in bone tissue and their involvement in bone remodeling. Microsc Res Tech 58:85-90

25. Johansson L, Edlund U, Fahlgren A, Aspenberg P (2009) Bone resorption induced by fluid flow. J Biomech Eng 131:094505

26. Joy G, Patzakis MJ, Harvey JP Jr (1974) Precise evaluation of the reduction of severe ankle fractures. $J$ Bone Joint Surg Am 56:979-993

27. Junqueira L, Carneiro J, Kelly R (2007) Kraakbeen. In: Functionele Histologie, 11th edn. Elsevier, Maarssen, pp 140-147

28. Kiaer T, Pedersen NW, Kristensen KD, Starklint H (1990) Intraosseous pressure and oxygen tension in avascular necrosis and osteoarthritis of the hip. J Bone Joint Surg Br 72:1023-1030

29. Koch S, Kampen WU, Laprell H (1997) Cartilage and bone morphology in osteochondritis dissecans. Knee Surg Sports Traumatol Arthrosc 5:42-45

30. Koshino T, Wada S, Ara Y, Saito T (2003) Regeneration of degenerated articular cartilage after high tibial valgus osteotomy for medial compartmental osteoarthritis of the knee. Knee $10: 229-236$

31. Lassus J, Salo J, Jiranek WA, Santavirta S, Nevalainen J, Matucci-Cerinic $M$ et al (1998) Macrophage activation results in bone resorption. Clin Orthop Relat Res 352:7-15

32. Lloyd J, Elsayed S, Hariharan K, Tanaka H (2006) Revisiting the concept of talar shift in ankle fractures. Foot Ankle Int 27:793796

33. Mach DB, Rogers SD, Sabino MC, Luger NM, Schwei MJ, Pomonis JD et al (2002) Origins of skeletal pain: sensory and sympathetic innervation of the mouse femur. Neuroscience 113:155-166

34. Maroudas A, Schneiderman R (1987) "Free" and "exchangeable" or "trapped" and "non-exchangeable" water in cartilage. J Orthop Res 5:133-138

35. Messner K (1993) Hydroxylapatite supported Dacron plugs for repair of isolated full-thickness osteochondral defects of the rabbit femoral condyle: mechanical and histological evaluations from 6 to 48 weeks. J Biomed Mater Res 27:1527-1532

36. Millington S, Grabner M, Wozelka R, Hurwitz S, Crandall J (2007) A stereophotographic study of ankle joint contact area. J Orthop Res 25:1465-1473

37. Mow VC, Flatow EL, Ateshian GA (2000) Biomechanics. In: Orthopaedic Basic Science: Biology and Biomechanics of the Musculoskeletal System, 2nd edn. American Academy of Orthopaedic Surgeons, Rosemont, pp 133-180
38. Nakamae A, Engebretsen L, Bahr R, Krosshaug T, Ochi M (2006) Natural history of bone bruises after acute knee injury: clinical outcome and histopathological findings. Knee Surg Sports Traumatol Arthrosc 14:1252-1258

39. Procter P, Paul JP (1982) Ankle joint biomechanics. J Biomech 15:627-634

40. Qiu YS, Shahgaldi BF, Revell WJ, Heatley FW (2003) Observations of subchondral plate advancement during osteochondral repair: a histomorphometric and mechanical study in the rabbit femoral condyle. Osteoarthritis Cartilage 11:810-820

41. Quinn TM, Allen RG, Schalet BJ, Perumbuli P, Hunziker EB (2001) Matrix and cell injury due to sub-impact loading of adult bovine articular cartilage explants: effects of strain rate and peak stress. J Orthop Res 19:242-249

42. Radin EL, Burr DB (1984) Hypothesis: joints can heal. Semin Arthritis Rheum 13:293-302

43. Radin EL, Rose RM (1986) Role of subchondral bone in the initiation and progression of cartilage damage. Clin Orthop Relat Res 213:34-40

44. Ramsey PL, Hamilton W (1976) Changes in tibiotalar area of contact caused by lateral talar shift. J Bone Joint Surg Am $58: 356-357$

45. Rangger C, Kathrein A, Freund MC, Klestil T, Kreczy A (1998) Bone bruise of the knee: histology and cryosections in 5 cases. Acta Orthop Scand 69:291-294

46. Ray R, Coughlin E (1947) Osteochondritis dissecans of the talus. J Bone Joint Surg 29:697-706

47. Reilingh ML, van Bergen CJ, van Dijk CN (2009) Diagnosis and treatment of osteochondral defects of the ankle. South Afr Orthop J 8:44-50

48. Roemer FW, Bohndorf K (2002) Long-term osseous sequelae after acute trauma of the knee joint evaluated by MRI. Skeletal Radiol 31:615-623

49. Saxler G, Loer F, Skumavc M, Pfortner J, Hanesch U (2007) Localization of SP- and CGRP-immunopositive nerve fibers in the hip joint of patients with painful osteoarthritis and of patients with painless failed total hip arthroplasties. Eur J Pain 11:67-74

50. Schachter AK, Chen AL, Reddy PD, Tejwani NC (2005) Osteochondral lesions of the talus. J Am Acad Orthop Surg 13:152-158

51. Schmalzried TP, Akizuki KH, Fedenko AN, Mirra J (1997) The role of access of joint fluid to bone in periarticular osteolysis. A report of four cases. J Bone Joint Surg Am 79:447-452

52. Schuman L, Struijs PA, van Dijk CN (2002) Arthroscopic treatment for osteochondral defects of the talus. Results at follow-up at 2 to 11 years. J Bone Joint Surg Br 84:364-368

53. Scranton PE Jr, McDermott JE (2001) Treatment of type V osteochondral lesions of the talus with ipsilateral knee osteochondral autografts. Foot Ankle Int 22:380-384

54. Shapiro F, Koide S, Glimcher MJ (1993) Cell origin and differentiation in the repair of full-thickness defects of articular cartilage. J Bone Joint Surg Am 75:532-553

55. Shepherd DE, Seedhom BB (1999) Thickness of human articular cartilage in joints of the lower limb. Ann Rheum Dis 58:27-34

56. Simon WH, Friedenberg S, Richardson S (1973) Joint congruence. A correlation of joint congruence and thickness of articular cartilage in dogs. J Bone Joint Surg Am 55:1614-1620

57. Specchiulli F, Capocasale N, Laforgia R, Solarino GB (1987) The surgical treatment of idiopathic osteonecrosis of the femoral head. Ital J Orthop Traumatol 13:345-351

58. Stone JW (1996) Osteochondral lesions of the talar dome. J Am Acad Orthop Surg 4:63-73

59. Sugimoto K, Takakura Y, Tohno Y, Kumai T, Kawate K, Kadono $\mathrm{K}$ (2005) Cartilage thickness of the talar dome. Arthroscopy 21:401-404 
60. Tarr RR, Resnick CT, Wagner KS, Sarmiento A (1985) Changes in tibiotalar joint contact areas following experimentally induced tibial angular deformities. Clin Orthop Relat Res 199:72-80

61. Thordarson DB, Motamed S, Hedman T, Ebramzadeh E, Bakshian S (1997) The effect of fibular malreduction on contact pressures in an ankle fracture malunion model. J Bone Joint Surg Am 79:1809-1815

62. Torzilli PA, Grigiene R, Borrelli J Jr, Helfet DL (1999) Effect of impact load on articular cartilage: cell metabolism and viability, and matrix water content. J Biomech Eng 121:433-441

63. Uozumi H, Sugita T, Aizawa T, Takahashi A, Ohnuma M, Itoi E (2009) Histologic findings and possible causes of osteochondritis dissecans of the knee. Am J Sports Med 37:2003-2008

64. van der Vis HM, Aspenberg P, Marti RK, Tigchelaar W, Van Noorden CJ (1998) Fluid pressure causes bone resorption in a rabbit model of prosthetic loosening. Clin Orthop Relat Res 350:201-208
65. Vellet AD, Marks PH, Fowler PJ, Munro TG (1991) Occult posttraumatic osteochondral lesions of the knee: prevalence, classification, and short-term sequelae evaluated with MR imaging. Radiology 178:271-276

66. Verhagen RA, Struijs PA, Bossuyt PM, van Dijk CN (2003) Systematic review of treatment strategies for osteochondral defects of the talar dome. Foot Ankle Clin 8:233-242

67. Wan L, de Asla RJ, Rubash HE, Li G (2008) In vivo cartilage contact deformation of human ankle joints under full body weight. J Orthop Res 26:1081-1089

68. Woods K, Harris I (1995) Osteochondritis dissecans of the talus in identical twins. J Bone Joint Surg Br 77:331

69. Yamamoto T, Bullough PG (2000) Spontaneous osteonecrosis of the knee: the result of subchondral insufficiency fracture. J Bone Joint Surg Am 82:858-866

70. Zengerink M, Struijs PA, Tol JL, van Dijk CN (2009) Treatment of osteochondral lesions of the talus: a systematic review. Knee Surg Sports Traumatol Arthrosc. doi:10.1007/s00167-009-0942-6 